\title{
Effect of Air Injection on Nucleation Rates \\ An Approach from Induction Time Statistics
}

Capellades Mendez, Gerard; Kiil, Søren; Dam-Johansen, Kim; Mealy, Michael J.; Christensen, Troels V. ; Myerson, Allan S.

Published in:

Crystal Growth \& Design

Link to article, DOI:

10.1021/acs.cgd.7b00267

Publication date:

2017

Document Version

Peer reviewed version

Link back to DTU Orbit

Citation (APA):

Capellades Mendez, G., Kiil, S., Dam-Johansen, K., Mealy, M. J., Christensen, T. V., \& Myerson, A. S. (2017). Effect of Air Injection on Nucleation Rates: An Approach from Induction Time Statistics. Crystal Growth \& Design, 17(6), 3287-3294. https://doi.org/10.1021/acs.cgd.7b00267

\section{General rights}

Copyright and moral rights for the publications made accessible in the public portal are retained by the authors and/or other copyright owners and it is a condition of accessing publications that users recognise and abide by the legal requirements associated with these rights.

- Users may download and print one copy of any publication from the public portal for the purpose of private study or research.

- You may not further distribute the material or use it for any profit-making activity or commercial gain

- You may freely distribute the URL identifying the publication in the public portal 
Effect of Air Injection on Nucleation Rates - an Approach from Induction Time Statistics

Gerard Capellades, ${ }^{\dagger, \dagger}$ Søren Kiil, ${ }^{\dagger}$ Kim Dam-Johansen, ${ }^{\dagger}$ Michael J. Mealy ${ }^{\dagger}$ Troels V. Christensen ${ }^{\ddagger}$ and Allan S. Myerson*,§

$\dagger$ Department of Chemical and Biochemical Engineering, Technical University of Denmark, DTU, Building 229, 2800 Kgs. Lyngby, Denmark

† H. Lundbeck A/S, Oddenvej 182, 4500 Nykøbing Sjælland, Denmark

$\S$ Department of Chemical Engineering, Massachusetts Institute of Technology, E19-502D, 77 Massachusetts Avenue, Cambridge, Massachusetts 02139-4307, United States

Injection of saturated air has been investigated as a method to enhance nucleation rates in batch crystallizers. When using probability distributions of induction times, the slope of the distribution gives an indication on the rate of primary nucleation, while the intercept shows the time elapsed from formation of the first crystal to detection by the instrument. Injecting gas throughout the entire period, we obtained a 5-fold reduction in the detection delay for two model compounds, demonstrating that the flowing gas was able to promote secondary nucleation and crystal growth. While primary nucleation was impacted by mixing intensity for both compounds, only one of them exhibited a detectable change with air injection.
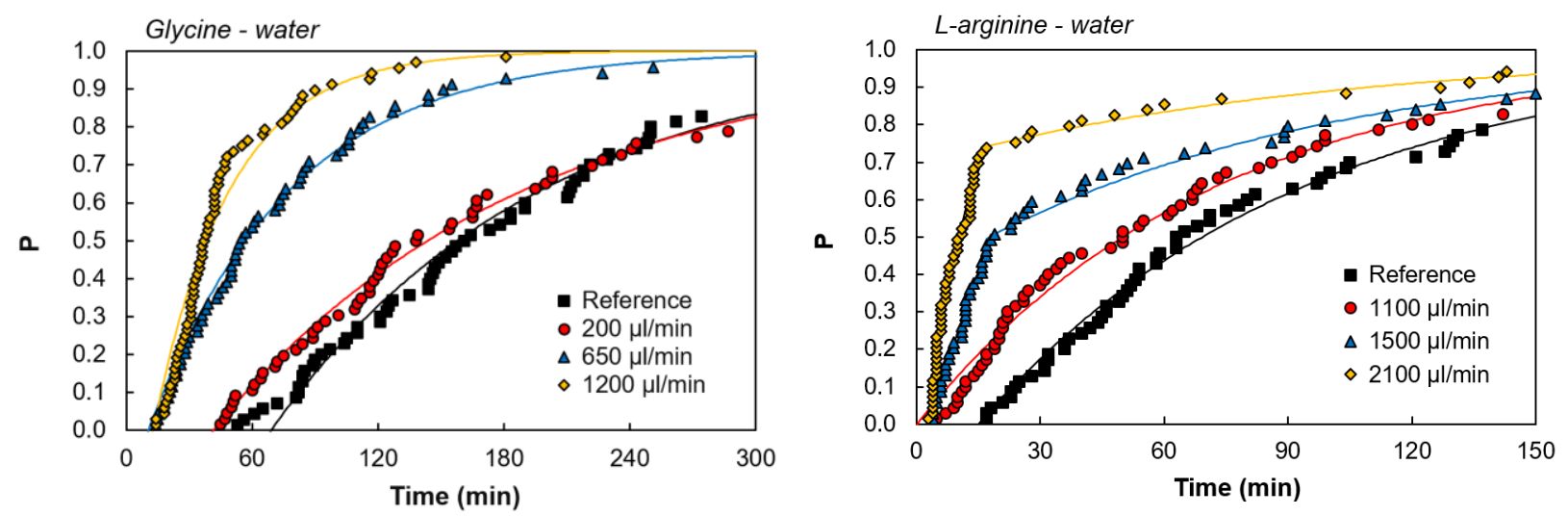

\section{Allan S. Myerson}

77 Massachusetts Avenue

Cambridge, Massachusetts

02139-4307
Phone 617-452- 3790

Fax 617-253-2072

Emailmyerson@mit.edu 


\title{
Effect of Air Injection on Nucleation Rates - an
}

\section{Approach from Induction Time Statistics}

Gerard Capellades, ${ }^{\not+\dagger}$ Søren Kiil,${ }^{\dagger}$ Kim Dam-Johansen, ${ }^{\dagger}$ Michael J. Mealy, ${ }^{\ddagger}$ Troels V. Christensen ${ }^{*}$ and Allan S. Myerson* $* \$$

$\dagger$ Department of Chemical and Biochemical Engineering, Technical University of Denmark, DTU, Building 229, 2800 Kgs. Lyngby, Denmark

\$ H. Lundbeck A/S, Oddenvej 182, 4500 Nykøbing Sjælland, Denmark

$\S$ Department of Chemical Engineering, Massachusetts Institute of Technology, E19-502D, 77

Massachusetts Avenue, Cambridge, Massachusetts 02139-4307, United States

Corresponding author e-mail: myerson@mit.edu.

\begin{abstract}
From disruption of the supersaturated solution to improved mass transfer in the crystallizing suspension, the introduction of a moving gas phase in a crystallizer could lead to improved rates of nucleation and crystal growth. In this work, saturated air has been injected to batch crystallizers to study the effects on formation of the first crystal and subsequent turbidity buildup. To account for the typically large sample-to-sample variation, nucleation rates were evaluated for a large number of replicates using probability distributions of induction times. The slope and the intercept of the distributions were studied independently, allowing the
\end{abstract}


simultaneous determination of the mean induction time and a certain detection delay related to the rate of crystal growth after formation of the first nucleus. Injecting saturated air in aqueous glycine solutions, the average detection delay was reduced from $69 \mathrm{~min}$ to $13 \mathrm{~min}$, and the mean induction time decreased from $128 \mathrm{~min}$ to $36 \mathrm{~min}$. The effect on aqueous solutions of L-arginine was less apparent, with a detection delay reduction from $15 \mathrm{~min}$ to $3 \mathrm{~min}$, and no significant changes on the rate of primary nucleation. These results demonstrate the potential of this technique for reduction in nucleation induction time and improved mass deposition rates in crystallization operations.

\section{INTRODUCTION}

Crystallization is an important separation technique that is extensively used in the chemical, food and pharmaceutical industries. Especially in pharmaceutical production, the crystallized solids are subject to strict quality requirements regarding crystal purity, polymorphism and size distribution. ${ }^{1}$ Nucleation plays a fundamental role when defining these quality attributes. Thus, an important part of the recent crystallization research is aimed at achieving a better understanding of this phenomenon. ${ }^{2}$

Transition to the crystalline phase starts with the formation of the first nucleus in a supersaturated solution. This event is stochastic and based on a certain probability that is related to the primary nucleation rate. ${ }^{3-5}$ Several factors can affect the probability of observing a primary nucleation event in a crystallizer, mainly: sample volume, supersaturation, temperature, mixing and the presence of impurities. ${ }^{5,6}$ Once the first nucleus is formed, solute crystals are present in the system and secondary nucleation can occur. Systems with crystals present have the advantage of producing additional nuclei through secondary nucleation thus increasing the mass deposition 
rate due to the higher surface area present in the crystalline phase. Secondary nucleation is highly dependent on agitation and becomes the predominant nucleation mechanism at low supersaturations. ${ }^{6}$ For the operation of industrial crystallizers, understanding the rates of nucleation and crystal growth is critical to obtain a product with the right size and form. ${ }^{1,7} \mathrm{~A}$ method to selectively enhance one of the two rates can therefore lead to significant advantages in process control.

The use of probabilistic methods to investigate nucleation kinetics dates back from more than 60 years. Some of the first studies were based on solidification in small droplets, using supercooled mercury, tin and water. ${ }^{8-10}$ In recent work, probability distributions of induction times have been applied for the evaluation of new methods for control of nucleation rates and polymorphism by using polymer surfaces or gels. ${ }^{11-14}$ The extended use of primary nucleation studies led to the development of novel equipment employing microfluidics to accommodate a large number of replicates in a single experiment. ${ }^{15-17}$

Dispersion of a saturated gas in the active crystallization volume has been postulated to enhance primary nucleation through different mechanisms. Bubble flow and collapse cause a mechanical disruption in the supersaturated solution that could have a similar effect to that seen with the application of mixing. In addition, it is frequently stated that the gas-liquid interphase could promote nucleation by acting as a heterogeneous nucleation site. ${ }^{18-22}$ In systems limited by mass transfer, mixing induced by the flowing gas would enhance the rate of crystallization at constant supersaturation. When solute crystals are present, perturbations in the flow direction would promote the contact frequency between crystals and enhance the rate of secondary nucleation. These mechanisms would be the most interesting for industrial crystallization, as they 
would allow gas recirculation without pre-treatment. Alternatively, cold unsaturated gas could be used as a means to induce local supersaturation changes by solvent evaporation and heat transfer.

Previous studies have dealt with the application of gassing to induce nucleation in batch crystallizers. ${ }^{20-23}$ However, due to the complexity of the system and the various ways that gassing could influence primary nucleation, the mechanism is not yet fully understood.

In this study, a probabilistic approach based on induction times has been applied to crystallization under air injection. The statistical significance of kinetic changes caused by the application of gas is evaluated taking into account the existing variation between induction time measurements. The experiments are carried out under continuous saturated air injection and carefully designed to minimize the impact of heat transfer, evaporation or gas expansion on supersaturation of the metastable solutions. Combining the use of probability distributions and a detection method based on sample turbidity allowed decoupling the average time for crystal formation from the time required to achieve a certain solution turbidity. Thus, this study deals with the effect that the presence of a flowing gas would have on (1) the time for formation of the first crystal and (2) turbidity build-up after the first nucleation event.

\section{EXPERIMENTAL SECTION}

Materials. Glycine ( $\geq 99.5 \%$ purity) was purchased from Alfa Aesar, Haverhill, USA. Larginine ( $\geq 98 \%$ purity) was purchased from Sigma-Aldrich, St. Louis, USA. Deionized water was used as the solvent for both compounds. For the experiments involving gas injection, compressed air from the laboratory general supply was selected as the gas phase.

Experimental setup. A schematic of the experimental setup for the air injection experiments is illustrated in Figure 1. The air feed is mixed with steam in a boiler and passed through two 
condensers to remove the excess water. A temperature/relative humidity data logger (Sper Scientific, Scottsdale, USA) is connected to the end of the second condenser to monitor the air properties. Based on the logged data, the heat supplied to the boiler and the temperature of the cooling water are manually adjusted to keep the air saturation with solvent above $95 \%$ at $25{ }^{\circ} \mathrm{C}$. The saturated air is distributed to 16 parallel crystallizers through a set of manifolds, and the flow rate at each of the streams is adjusted with an independent needle valve. Air injection is conducted through PEEK ${ }^{\text {TM }}$ tubing (Upchurch Scientific ${ }^{\circledR}$; ID: $0.75 \mathrm{~mm}$, OD: 1/16”), immersed $27 \mathrm{~mm}$ from the top of the vial cap. To prevent leaks in the setup and cooling from air expansion, the pressure of the injected air is measured with a manometer and kept below the lower detection limit (0.34 barg). Accordingly, air cooling from Joule-Thomson expansion is maintained under $0.08{ }^{\circ} \mathrm{C}^{24}$ A Crystal16 ${ }^{\circledR}$ multiple reactor setup (Avantium Research \& Technology) is used to control the temperature and agitation rate in the crystallizers. The crystallizers are cylindrical vials with a maximum capacity of $2 \mathrm{ml}$ and $10 \mathrm{~mm}$ internal diameter. Sample mixing is obtained through magnetic stirring with PTFE agitation bars (cylindrical, $8 \mathrm{~mm} \times 3 \mathrm{~mm}$ ). During the induction time measurements, the nucleation event is detected by the Crystal16 ${ }^{\circledR}$ unit as a drop in light transmission through each sample.

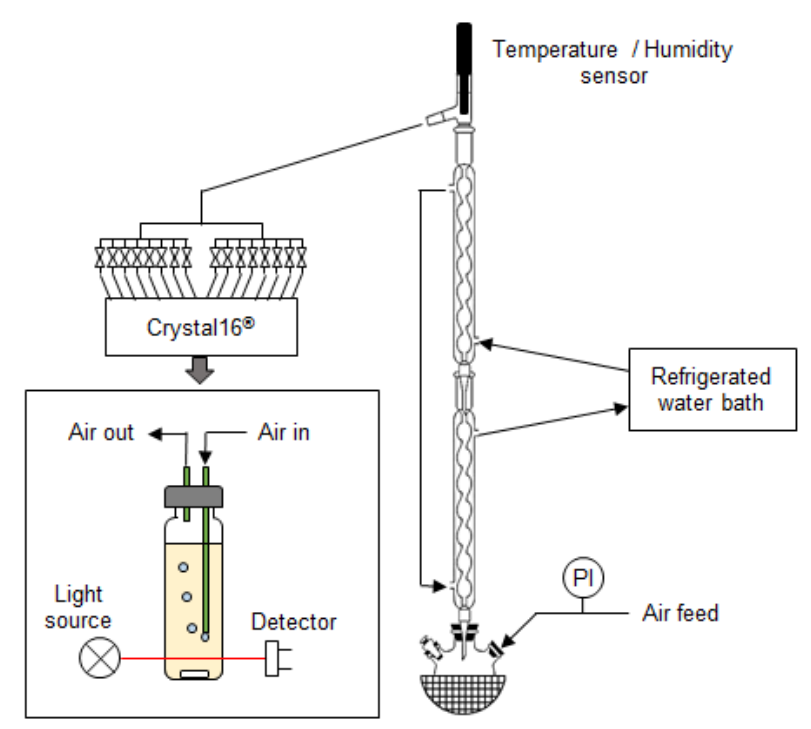


Figure 1. Schematic diagram of the experimental setup for the induction time measurements with saturated air injection.

Sample preparation and Crystal16 ${ }^{\circledR}$ program. $60 \mathrm{~g}$ stock suspensions are prepared with different weight fractions of the corresponding solute and demineralized water. These suspensions are dissolved at $60-70{ }^{\circ} \mathrm{C}$ before the clear solution is pipetted to the sample vials. A sample volume of $1.40 \mathrm{ml}$ is selected for the experiments throughout this work.

To ensure that the induction time measurements start from a crystal free solution, the unit is programmed to pre-heat the samples to at least $10{ }^{\circ} \mathrm{C}$ above their saturation temperature for 30 minutes. The samples are then quenched ( 3 minutes) and the induction times are measured at 25 ${ }^{\circ} \mathrm{C}$ with a studied time frame of 300 minutes for glycine and 150 minutes for L-arginine.

Induction time measurements at variable supersaturations. A first set of induction time measurements was conducted to quantify the effect of supersaturation on nucleation and growth kinetics. These experiments have three functions: (1) to demonstrate that the induction times follow a Poisson distribution for the studied range of kinetics, (2) to determine a supersaturation ratio for the experiments with air injection, and (3) to study the sensitivity of each solute to concentration changes that could arise from solvent evaporation. The measurements were conducted at $300 \mathrm{rpm}$ and in the absence of injection tubing. The studied supersaturation ratios are $1.20,1.23,1.26,1.31,1.42$ for glycine ${ }^{25}$ and $1.23,1.29,1.35,1.46,1.58$ for L-arginine. $^{26}$ Here, the supersaturation ratio is defined as $\mathrm{S}=\mathrm{C} / \mathrm{C}_{\text {sat }}$, where $\mathrm{C}$ is the solute weight fraction at the stock solution and $\mathrm{C}_{\text {sat }}$ is the solute weight fraction at the saturated solution at $25^{\circ} \mathrm{C}$.

Crystallization under continuous air injection. A series of induction time measurements were conducted using the setup illustrated in Figure 1. These experiments were performed with different air flow rates while keeping a constant supersaturation and mixing $(300 \mathrm{rpm})$ in the 
samples. Reference measurements were conducted without air injection while using the same tubing and immersion.

The temperature of the samples was kept at $25^{\circ} \mathrm{C}$ throughout the induction time measurements to prevent condensation and significant cooling in the manifold system. The supersaturation ratios for the aqueous glycine and L-arginine solutions were maintained at 1.20 and 1.23, respectively. These values were carefully selected so that at least $50 \%$ of the samples crystallize within the measurement time frame, giving enough points for data treatment, and to ensure that the detection delays are large enough to study changes in the rate of turbidity build-up. Lower supersaturations were avoided as the attainable turbidities were not high enough for a clear detection.

The temperature of the samples at the pre-heating step was maintained at $50{ }^{\circ} \mathrm{C}$ for all the samples. To minimize solvent evaporation during this step, the air flow was disconnected until two minutes before crash cooling. The air flow rate was then visually adjusted for each of the streams and the system was videotaped for later quantification of the flow rate.

At the end of the experiments, the weight loss was measured for each of the samples to quantify the effect of solvent evaporation on supersaturation. Then, the crystallized samples were filtered together and washed with demineralized water. To identify possible changes in the crystallized polymorphs, X-Ray Powder Diffraction (XRPD) patterns of the filtered crystals were obtained for $2 \theta$ between $5^{\circ}$ and $40^{\circ}$ using an X'PertPro PanAnalytical diffractometer.

Effect of increased mixing on primary nucleation. As an approach to study the mechanism behind the system behavior with air injection, induction time measurements were conducted at constant supersaturation with mixing intensities of $500 \mathrm{rpm}$ and $700 \mathrm{rpm}$. These measurements 
provide with a quantitative indication on the sensitivity of the system to changes in the mixing conditions. The experiments were performed in the absence of injection tubing.

Theoretical basis and data treatment. In this work, the observed effects on crystallization kinetics have been evaluated on the basis of probability distributions of induction times. For an unseeded system, the time elapsed between the achievement of a constant supersaturation ratio until formation of the first nucleus has been defined as the induction time. The first nucleation event does not occur at a fixed point in time but it is based on a certain probability, which is a function of the primary nucleation rate and the sample volume. For a system with constant volume, changes in the rate of primary nucleation can be studied from the slope of a Poisson distribution containing the induction time measurements for a large number of replicates. ${ }^{9}$

In practice, the nucleation event is not observed until the crystals have grown to be detectable. Different detection methods can lead to significant variations in the observed induction times. For methods based on microscope observations, the formed nucleus has to grow to a certain size before the nucleation event is confirmed. When detection is based on turbidity measurements, a certain extent of crystallization will be required through primary nucleation, secondary nucleation and crystal growth. For agitated systems at low supersaturation, secondary nucleation and crystal growth tend to be the dominant mechanisms for turbidity build-up. This mechanism is illustrated in Figure 2 and further evaluated in the discussion section.

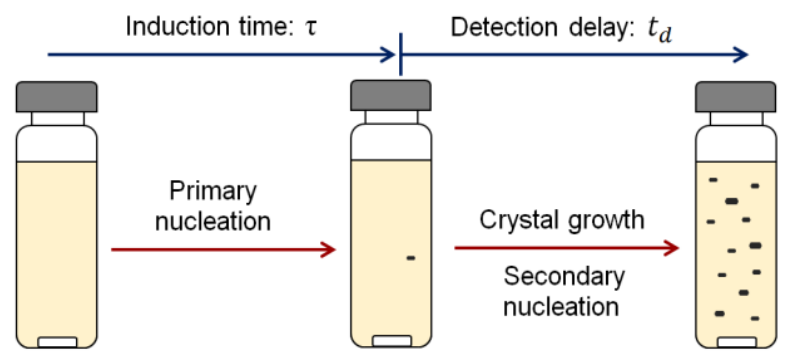


Figure 2. Illustration of the steps from achievement of a constant supersaturation to nucleation detection from sample turbidity.

For the same detection instrument and using systems with sufficient agitation, the minimum detectable turbidity will have a fixed value. Thus, variations in the rates of crystal growth and secondary nucleation can be studied from variations in the observed detection delay.

In this work, the induction time measurements were converted into a probability distribution by use of the following equation:

$$
P(t)=\frac{\xi^{\prime}(t)}{\xi}
$$

where $\xi^{\prime}(t)$ is the number of samples that nucleated before time $t$, and $\xi$ is the total amount of replicates at the studied conditions.

For a system following a Poisson distribution, the probability $\mathrm{P}(\mathrm{t})$ of detecting crystals at time $\mathrm{t}$ can be related to the mean induction time $\tau$ as: $:^{4,27}$

$$
P(t)=1-\exp \left(-\frac{t}{\tau}\right)
$$

Eq 2 is valid as long as the detection delay is sufficiently small compared to the mean induction time. Especially for slow growing compounds or for detection methods based on sample turbidity, the probability distributions tend to be shifted in the time axis. Previous work accounted for this shift by defining the time for appearance of the nucleus as the time at which nucleation is detected minus the detection delay. ${ }^{17,28}$ Eq 2 has been modified in a similar way:

$$
P(t)=1-\exp \left(-\frac{t-t_{d}}{\tau}\right)
$$

where $t_{d}$ is the average detection delay at the experimental conditions. The values of $\tau$ and $t_{d}$ were obtained from linear regression using the logarithmic form of eq 3. 


\section{RESULTS}

Supersaturation effect on crystallization kinetics. In the first set of experiments, induction times were measured at different supersaturations for the aqueous solutions of the two model compounds. The obtained probability distributions and the fitted kinetics are reported in Figure 3 and Table 1, respectively.
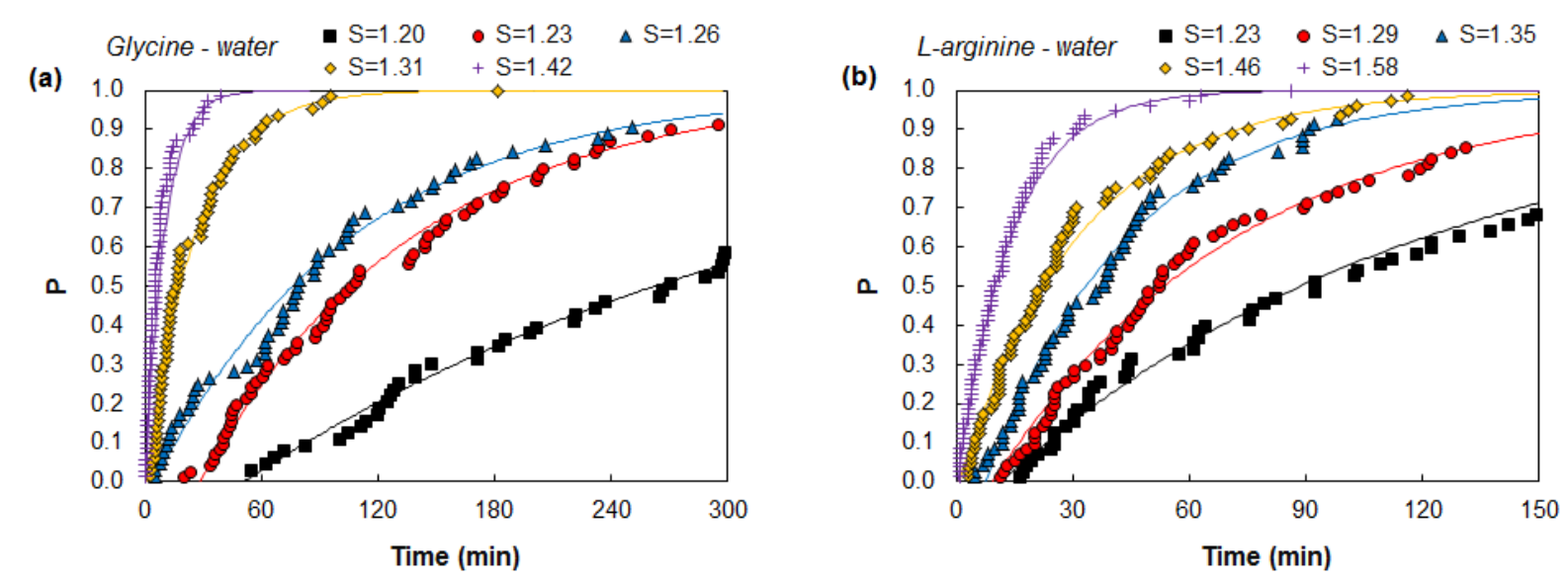

Figure 3. Cumulative probability distributions of induction times for aqueous solutions of glycine (a) and L-arginine (b) at different supersaturations. Each point represents the observed induction time of an independent crystallization experiment. The solid lines are the theoretical distributions based on the fit to eq 3. Sample volume: $1.40 \mathrm{ml}$. Mixing: $300 \mathrm{rpm}$. Temperature: $25{ }^{\circ} \mathrm{C}$.

The observed induction times follow a Poisson distribution throughout the experiment time frame, giving a good fit $\left(\mathrm{r}^{2}>0.98\right)$ to the logarithmic form of eq 3 . As expected, higher supersaturations lead to shorter induction times. The increased rate of primary nucleation is graphically observed from the slope of the distributions and quantified as drop in the mean induction time. The mean detection delay is graphically observed from the intercept of the plots 
with the time axis. Higher supersaturations lead to faster rates of nucleation and crystal growth, effectively lowering the time required to achieve the minimum detectable turbidity.

Table 1. Fitted mean induction times $(\tau)$ and detection delays $\left(t_{d}\right)$ for different suprersaturation ratios (S), including 95\% confidence intervals from linear regression.

$\begin{array}{ccccc} & \mathrm{S}\left(25^{\circ} \mathrm{C}\right) & \tau(\min ) & \mathrm{t}_{\mathrm{d}}(\mathrm{min}) & \mathrm{r}^{2} \\ \text { Glycine } & 1.20 & 305 \pm 12 & 51 \pm 7 & 0.987 \\ 1.23 & 111 \pm 3 & 28 \pm 3 & 0.991 \\ 1.26 & 103 \pm 3 & 5 \pm 3 & 0.986 \\ 1.31 & 25 \pm 1 & 1 \pm 1 & 0.987 \\ & 1.42 & 10 \pm 0 & -1 \pm 1 & 0.966 \\ \text { L-arginine } & 111 \pm 4 & 11 \pm 4 & 0.980 \\ & 1.23 & 64 \pm 2 & 9 \pm 2 & 0.987 \\ & 1.35 & 37 \pm 1 & 7 \pm 1 & 0.986 \\ & 1.46 & 31 \pm 1 & 1 \pm 1 & 0.983 \\ & 1.58 & 14 \pm 0 & 0 \pm 1 & 0.982\end{array}$

Crystallization with continuous air injection. Induction times were measured on samples with constant supersaturation and mixing, using the setup illustrated in Figure 1 and a continuous feed of saturated air. The air flow rates at the different experiments were determined in bubbles/min from the recorded video files of 40 random replicates. Using the outer diameter of the injection tubing as a reference, the mean bubble size was determined to be $2.1 \mathrm{~mm}$. Then, the flow rate was converted from bubbles/min to $\mu \mathrm{l} / \mathrm{min}$ assuming that the bubbles have a consistent size and a spherical shape. None of the samples presented foaming during the experiments with air injection. 
The obtained XRPD data for the filtered crystals can be found in supporting information. Throughout the experiments in this block, both compounds crystallized in the same form regardless of the air flow rate. These forms are $\alpha$-glycine and L-arginine dihydrate. For the experiments with glycine-water and air injection at $650 \mu \mathrm{l} / \mathrm{min}$, traces of $\gamma$-glycine were found in one of the measurements. This is the most stable form thermodynamically, but it is rarely obtained at a neutral $\mathrm{pH}^{29}$ The probability of obtaining $\gamma$-glycine is very small at these conditions, but nucleation of this form is still possible. Since crystallization of $\gamma$-glycine was not reproducible, the observation was attributed to this existing low probability.
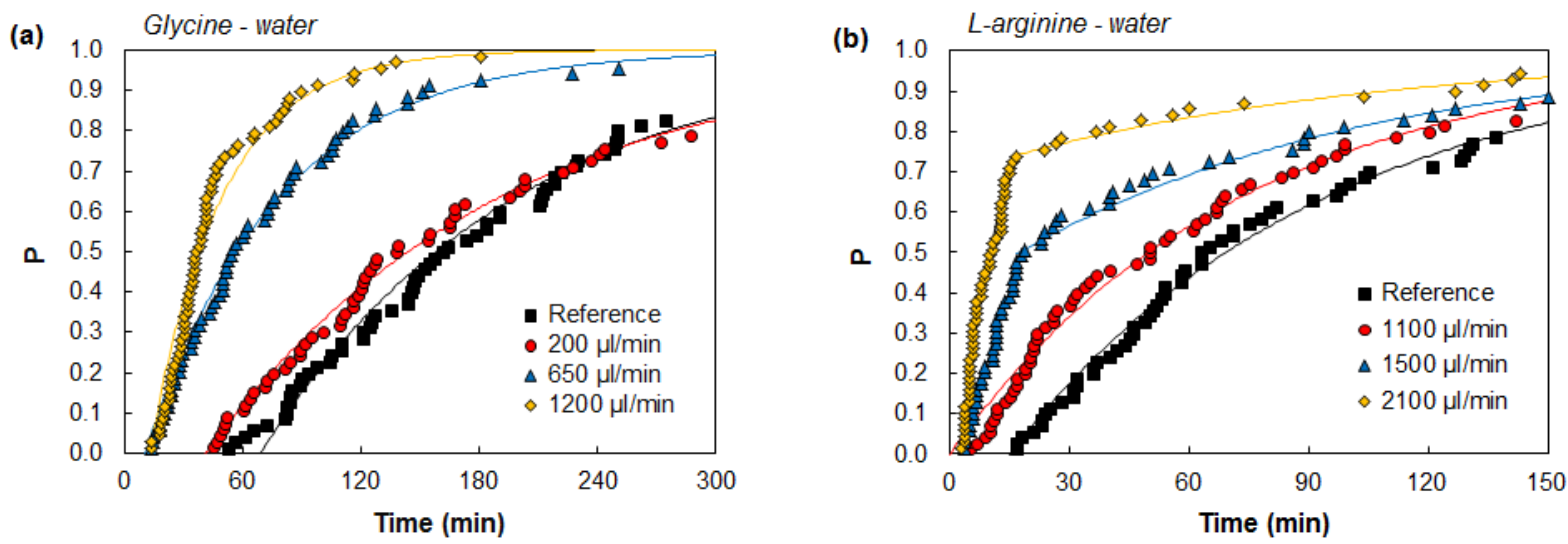

Figure 4. Cumulative probability distributions of induction times for aqueous solutions of glycine (a) and L-arginine (b) at different air flow rates. Each point represents the observed induction time of an independent crystallization experiment. The solid lines are the theoretical distributions based on the fit to eq 3. The distributions for L-arginine at air flow rates of $1500-$ $2100 \mu \mathrm{l} / \mathrm{min}$ exhibit a sudden slope change at time $=15 \mathrm{~min}$, indicating the appearance of a second regime with a lower frequency of nucleation. Sample volume: $1.40 \mathrm{ml}$. Mixing: $300 \mathrm{rpm}$. Temperature: $25^{\circ} \mathrm{C}$. Supersaturation: 1.20 (glycine) and 1.23 (L-arginine).

The observed induction times are reported in Figure 4. These results show that air injection had a positive effect on primary nucleation for glycine solutions, giving a 4-fold decrease in the mean 
induction time for an air flow rate of $1200 \mu \mathrm{l} / \mathrm{min}$. The effect on primary nucleation is directly related to the flow rate and subject to a minimum value. The smallest studied flow rate (200 $\mu \mathrm{l} / \mathrm{min}$ ) showed no detectable differences in the induction times.

Aqueous solutions of L-arginine show a different behavior with the injection of air. For this compound, an air flow rate of $1100 \mu \mathrm{l} / \mathrm{min}$ reduced the detection delay while maintaining a constant induction time. This behavior indicates that, despite the primary nucleation rate is independent of air injection at these conditions, the rates of secondary nucleation and crystal growth are still enhanced.

Flow rates at or above $1500 \mu \mathrm{l} / \mathrm{min}$ gave distributions with two different regimes separated by a sudden slope change at $t=15 \mathrm{~min}$. The appearance of a second regime would be expected if a fraction of the samples had a significantly different primary nucleation rate. In the previous set of experiments (Figure 3), similar distribution slopes were obtained with a single regime by increasing the supersaturation of the samples. Thus, this behavior is exclusive for the experiments with air injection.

Multiple nucleation rates have been previously attributed to variations in the concentration of active sites between replicates, coming from different distributions of impurities or differenciated surface properties in the solids present in the samples. ${ }^{14,30,31}$ In this work, variations in the amount of nucleation sites were prevented by using the same tubes for all the experiments as well as preparing samples from the same stock solution. XRPD data also shows that both regimes gave the same crystal form of L-arginine. Thus, crystallization of multiple polymorphs has been discarded to explain the appearance of a second regime.

The multiple regime behavior was accompanied by the observation of crystals at the injection point of some samples 5 - 10 min after quenching (see Figure 5). This phenomenon was only 
observed at the start of the experiments and for flow rates above $1200 \mu 1 / \mathrm{min}$. It could be explained as consequence of crystal formation during the pre-heating step. Before crash cooling, saturated air is being injected at $25{ }^{\circ} \mathrm{C}$ to the undersaturated solution at $50{ }^{\circ} \mathrm{C}$. When the air flow rate is high enough, local evaporation combined with cooling could lead to the formation of small crystals at the tube tip. These crystals would then grow as the bulk solution becomes supersaturated.

Formation of crystals during the pre-heating step would be able to explain the multiple regime behavior of the distributions. Neither the formation of crystals at the tube tip nor the multiple regime were observed at flow rates below $1500 \mu 1 / \mathrm{min}$, presumably because heat transfer and evaporation rate are not sufficient to maintain a local supersaturation during the pre-heating step.

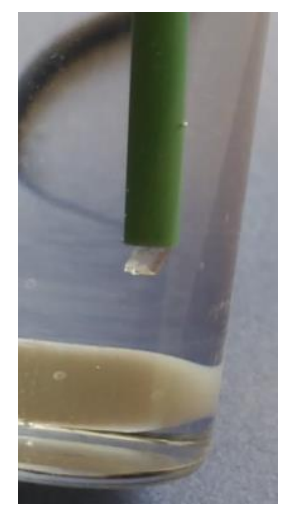

Figure 5. L-arginine crystal blocking the air injection point a few minutes after crash cooling.

To account for this phenomenon, the average induction times were determined only from the slope of the second regime. Assuming that the source of the first crystal does not significantly affect the rate of turbidity build-up, the average detection delay could be obtained from linear regression of the observed induction times within the first $15 \mathrm{~min}$. Note that the accuracy of these calculations is severely lowered. The impact of temperature variations between sample cells and surface variations in the tubing was previously included in the reference samples. 
However, when data fitting is separated in two time frames, the samples with the lower temperatures and higher surface irregularities in the tubing are more likely to fall within the first slope, affecting the slope of the second half of the distribution. The experimental results obtained with this method should therefore lead to conclusions only if the observed induction times show a strong deviation from the reference values. The fitted induction times and detection delays are summarized in Table 2.

Table 2. Fitted mean induction times $(\tau)$ and detection delays $\left(t_{d}\right)$ for the experiments with air injection, including $95 \%$ confidence intervals from linear regression.

$\begin{array}{cccccc} & \begin{array}{c}\text { Flow rate } \\ (\mu \mathrm{l} / \mathrm{min})\end{array} & \begin{array}{c}\text { Weight loss } \\ (\%)\end{array} & \tau(\mathrm{min}) & \mathrm{t}_{\mathrm{d}}(\mathrm{min}) & \mathrm{r}^{2} \\ \text { Glycine } & 0 & 0.15 \pm 0.08 & 128 \pm 5 & 69 \pm 7 & 0.976 \\ & 195 \pm 56 & 0.16 \pm 0.10 & 149 \pm 4 & 42 \pm 4 & 0.991 \\ & 651 \pm 89 & 0.25 \pm 0.11 & 67 \pm 2 & 11 \pm 3 & 0.981 \\ & 1237 \pm 182 & 0.51 \pm 0.23 & 36 \pm 1 & 13 \pm 2 & 0.977 \\ \text { L-arginine } & 0 & 0.22 \pm 0.12 & 78 \pm 3 & 15 \pm 2 & 0.986 \\ & 1110 \pm 150 & 0.34 \pm 0.13 & 72 \pm 2 & 0 \pm 2 & 0.987 \\ & 1544 \pm 287 & 0.37 \pm 0.17 & 88 \pm 5 & 3 \pm 1 & 0.974-0.973 \\ & 2111 \pm 397 & 0.43 \pm 0.18 & 97 \pm 11 & 3 \pm 0 & 0.975-0.956\end{array}$

Multiple $\mathrm{r}^{2}$ values come from linear regression on the first and the second regime, respectively.

A common trend for both compounds is a significant reduction in the detection delay with air injection. Interestingly, the detection delay stops decreasing after a certain flow rate. The minimum detection delay was not observed for the experiments at variable supersaturation (Figure 3), where induction times and detection delays always decreased together.

The impact of air injection on solvent evaporation is calculated from the difference between the weight loss at the end of the experiment and that of the reference samples. By pre-saturating 
the air at the solution temperature, the average weight loss from solvent evaporation is kept below $0.36 \%$ in glycine solutions. Note that the weight loss is measured after 5 hours of gassing. However, $75 \%$ of the samples with this weight loss crystallized within the first hour. The amount of solvent evaporated at the point of nucleation is thus negligible. Based on the observed weight losses, it is safe to assume that the effect of air injection on glycine solutions goes beyond solvent evaporation.

The impact of mixing on induction times. To achieve a better understanding on the sensitivity of the system to changes in the mixing intensity, induction time measurements were conducted at constant supersaturation with agitation rates of $500 \mathrm{rpm}$ and $700 \mathrm{rpm}$. Results are summarized in Figure 6 and Table 3.
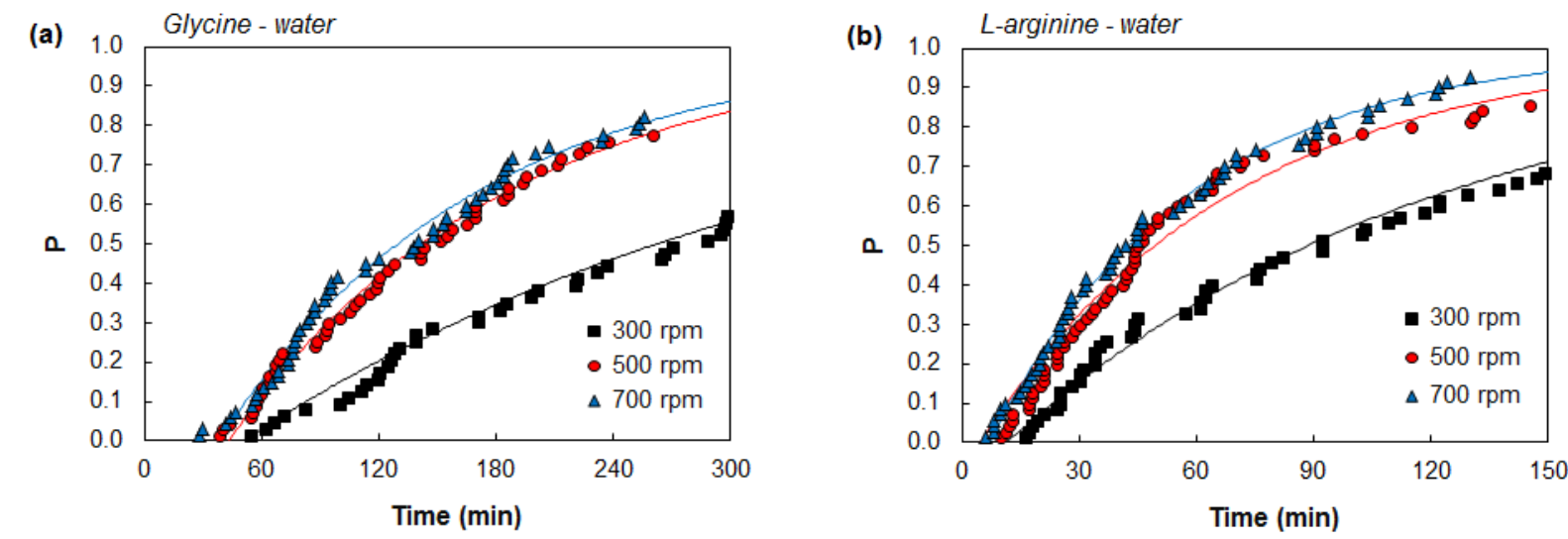

Figure 6. Cumulative probability distributions of induction times for aqueous solutions of glycine (a) and L-arginine (b) at constant supersaturation and different mixing intensities. Each point represents the observed induction time of an independent crystallization experiment. The solid lines are the theoretical distributions based on the fit to eq 3. Sample volume: $1.40 \mathrm{ml}$. Temperature: $25^{\circ} \mathrm{C}$. Glycine supersaturation: 1.20. L-arginine supersaturation: 1.23.

Mixing can enhance the rate of primary nucleation by promoting contact between solute molecules in solution, thus increasing the probability that a cluster with critical size is formed. 
However, it does not always have a positive effect. Previous work has shown that certain mixing intensities can lead to destabilization and breakage of the solute clusters. ${ }^{32,33}$ Our results show that increasing the impeller speed from $300 \mathrm{rpm}$ to $500 \mathrm{rpm}$ produced a 2 -fold decrease in the induction time for both compounds, but the effect of a higher mixing intensity (700 rpm) was barely noticeable. The investigated mixing intensities belong to the transitional mixing regime with impeller Reynolds numbers between 300 and 900. Thus, the observed change in behavior from $500 \mathrm{rpm}$ to $700 \mathrm{rpm}$ is not a consequence of a change in the mixing regime.

Table 3. Fitted mean induction times $(\tau)$ and detection delays $\left(t_{d}\right)$ for different mixing intensities, including 95\% confidence intervals from linear regression.

\begin{tabular}{ccccc} 
& $\begin{array}{c}\text { Mixer speed } \\
(\mathrm{rpm})\end{array}$ & $\tau(\min )$ & $\mathrm{t}_{\mathrm{d}}(\min )$ & $\mathrm{r}^{2}$ \\
\hline Glycine & 300 & $305 \pm 12$ & $51 \pm 7$ & 0.987 \\
& 500 & $142 \pm 4$ & $43 \pm 4$ & 0.991 \\
& 700 & $132 \pm 4$ & $38 \pm 5$ & 0.986 \\
L-arginine & 300 & $111 \pm 4$ & $11 \pm 4$ & 0.980 \\
& 500 & $64 \pm 4$ & $5 \pm 3$ & 0.987 \\
& 700 & $51 \pm 1$ & $7 \pm 1$ & 0.986
\end{tabular}

\section{DISCUSSION}

Effect of gas injection on primary nucleation. Results with aqueous glycine solutions show a 4-fold reduction in the mean induction time with the injection of saturated air. As supported by the large number of replicates and the measured weight losses, this effect goes beyond sampleto-sample variability and solvent evaporation. Enhancement of the primary nucleation rate was dependent on the air flow rate, and showed no detectable changes at $200 \mu \mathrm{l} / \mathrm{min}$. The underlying 
mechanism is presumably related to the perturbation of the supersaturated solution, which would be giving the required energy input for nucleation. This perturbation increases with the air flow rate and it would explain the observed correlation between induction times and injection flow rates. Results for L-arginine indicate that the mechanism goes beyond the increased mixing intensity. Despite both compounds were equally sensitive to increased stirring speeds, L-arginine showed no correlation between the air flow rate and the mean induction time. Were the effect of gas injection explained solely through the additional mixing intensity, both compounds would have shown a similar behavior to the application of air. The effect is thus related to changes in the mixing pattern or local perturbations from bubble collapse.

Alternatively, cluster stabilization at the gas-liquid interphase could have reduced the activation energy for nucleation if the air bubbles were acting as a heterogeneous nucleation site. The total gas-liquid interphase area increases with the flow rate, thus reducing the mean induction time. Since the effect was only observed for one of the two compounds, this mechanism could be sensitive to the system composition.

Mechanism for turbidity build-up. After formation of the first nuclei, the time required for achieving a certain turbidity depends on the combined rates of primary nucleation, secondary nucleation and crystal growth. The contribution of primary nucleation can be studied from the average induction times. Taking the experiments with glycine and an air injection of $650 \mu \mathrm{l} / \mathrm{min}$ as an example, the value of $\tau$ indicates that a primary crystal is formed, on average, every 67 minutes. However, the mean detection delay for this experiment is 11 minutes. Considering the much lower value of the detection delay and the fact that building a detectable turbidity requires a large amount of crystals, it is assumed that primary nucleation has a negligible contribution on turbidity after the first crystal is formed. In most of our samples, turbidity is expected to originate 
from a chain of crystal growth and secondary nucleation events. From the small rates of primary nucleation, this chain could have originated from a single crystal. This single nucleus mechanism was experimentally demonstrated in a similar system by Kadam et al. ${ }^{34}$

Effect of gas injection on crystal growth and secondary nucleation. Results from this work demonstrate that air injection is capable of producing a significant drop in the detection delay after the first nucleation event. This behavior was consistent for the two model systems and, in both cases, it is higher than the one observed for increased mixing intensities. In contrast with a faster impeller speed, the effect of gas flow in secondary nucleation could be explained by a change in the mixing direction. The stirring bar provides radial mixing in the sample. With higher agitation speeds, the formed crystals are expected to follow the liquid stream and collide mostly with the impeller and the vial walls. For the experiments with air injection, the upward air flow introduces axial mixing and thus perturbations in the mixing pattern. These perturbations become more important at higher gas flow rates, as they would increase the collision frequency between crystals and promote secondary nucleation. Higher liquid velocities are also expected after bubble collapse, which would promote collisions between nearby crystals.

In addition, were the growth rate in the system limited by diffusion, the improved mass transfer would have a positive effect on crystal growth. Bigger crystals not only contribute to a higher turbidity, but they are also more prone to sedimentation, thus increasing the contact frequency with the impeller and the rate of secondary nucleation.

The observed detection delays stop decreasing after a certain flow rate. This minimum detection delay was not observed for the experiments at variable supersaturation, where a reduction in the mean induction time was always paired with a drop in detection delay. The observed minimum on the detection delay is a consequence of a rate limiting factor. This factor 
is presumably crystal growth limited by surface incorporation, which would not be affected by the flowing gas in the system. The high detection delays observed for the glycine samples would be supported by the typically slow growth kinetics of this compound, especially at low supersaturations. ${ }^{35}$ Alternatively, the effect of gas injection on secondary nucleation could be highly sensitive to the suspension density in the system. When the crystals are originated from a single primary nucleation event, the effect of air flow on crystal collision will be negligible until a sufficient amount of crystals is present in the samples.

\section{CONCLUSIONS}

As an approach for a better understanding of the effect of a flowing gas on nucleation and growth kinetics, we have evaluated the effect of continuously injecting saturated air on the observed induction times for two model compounds. Results were analyzed on the basis of probability distributions with independent determination of the mean induction time and detection delay. We have shown that gas injection can have a positive effect on primary nucleation that is dependent on the gas flow rate. Comparing the effects of gas injection with the compound sensitivities to increased agitation rates, it is presumed that the effect goes beyond higher agitation intensities in the sample. Perturbations from the bubble flow and collapse or the presence of the gas-liquid interphase would have had an effect on the primary nucleation rate.

The detection delay dropped with air injection for the two model compounds, indicating that this technique has an effect on the rates of secondary nucleation or diffusion limited crystal growth. A minimum detection delay is observed for both compounds, indicating the presence of a rate limiting factor in turbidity build-up. This factor is presumably crystal growth limited by surface incorporation. 


\section{ASSOCIATED CONTENT}

\section{Supporting Information}

Logged temperature and relative humidity of the injected air, XRPD patterns of the samples crystallized with air injection. This material is available free of charge via the Internet at http://pubs.acs.org.

\section{AUTHOR INFORMATION}

\section{Corresponding Author}

*E-mail: myerson@mit.edu.

\section{Author Contributions}

The manuscript was written through contributions of all authors. All authors have given approval to the final version of the manuscript.

\section{Funding Sources}

This research was conducted as part of the first author's PhD study, which is funded by the Technical University of Denmark and H. Lundbeck A/S. Funding for the equipment used in this work was obtained from Massachusetts Institute of Technology.

\section{ACKNOWLEDGMENTS}

Financial support from the Technical University of Denmark, Massachusetts Institute of Technology and H. Lundbeck A/S is gratefully acknowledged. The first author would also like to 
acknowledge the Niels Bohr Foundation for support on the travel expenses associated with the research stay.

\section{REFERENCES}

(1) Tung, H. Org. Process Res. Dev. 2013, 17, 445-454.

(2) Chen, J.; Sarma, B.; Evans, J. M. B.; Myerson, A. S. Cryst. Growth Des. 2011, 11, 887-895.

(3) Turnbull, D. J. Chem. Phys. 1950, 18, 198-203.

(4) Toschev, S.; Milchev, A.; Stoyanov, S. J. Cryst. Growth. 1972, 13/14, 123-127.

(5) Kashchiev, D. Nucleation: Basic theory with applications; Butterworth-Heinemann: Oxford, 2000.

(6) Mullin, J. W. Crystallization; Butterworth-Heinemann: Oxford, 2001.

(7) Nagy, Z. K.; Braatz, R. D. Annu. Rev. Chem. Biomol. Eng. 2012, 3, 55-75.

(8) Vonnegut, B. J. Colloid Sci. 1948, 3, 563-569.

(9) La Mer, V. K.; Pound, G. M. J. Am. Chem. Soc. 1952, 74, 2323-2332.

(10) Turnbull, D. J. Chem. Phys. 1952, 20, 411-424.

(11) Tan, L.; Davis, R. M.; Myerson, A. S.; Trout, B. L. Cryst. Growth Des. 2015, 15, 21762186.

(12) Diao, Y.; Helgeson, M. E.; Myerson, A. S.; Hatton, T. A.; Doyle, P. S.; Trout, B. L. J. Am. Chem. Soc. 2011, 133, 3756-3759.

(13) Curcio, E.; López-Mejías, V.; Di Profio, G.; Fontananova, E.; Drioli, E.; Trout, B. L.; Myerson, A. S. Cryst. Growth Des. 2014, 14, 678-686.

(14) Diao, Y.; Whaley, K. E.; Helgeson, M. E.; Woldeyes, M. A.; Doyle, P. S.; Myerson, A. S.; Hatton, T. A.; Trout, B. L. J. Am. Chem. Soc. 2012, 134, 673-684.

(15) Ildefonso, M.; Candoni, N.; Veesler, S. Org. Process Res. Dev. 2012, 16, 556-560. 
(16) Ildefonso, M.; Revalor, E.; Punniam, P.; Salmon, J. B.; Candoni, N., Veesler, S. J. Cryst. Growth, 2012, 342, 9-12.

(17) Laval, P.; Salmon, J. B.; Joanicot, M. J. Cryst. Growth, 2007, 303, 622-628.

(18) Hem, S. L. Ultrasonics, 1967, 5, 202-207.

(19) Kulkarni, S. A.; Kadam, S. S.; Meekes, H.; Stankiewicz, A. I.; ter Horst, J. H. Cryst. Growth Des., 2013, 13, 2435-2440.

(20) Wohlgemuth, K.; Kordylla, A.; Ruether, F.; Schembecker, G. Chem. Eng. Sci., 2009, 64, 4155-4163.

(21) Ceyhan, A.; Baytar, O.; Pehlivan, E. Acta Chim. Slov., 2014, 61, 391-397.

(22) Kleetz, T.; Funke, F.; Sunderhaus, A.; Schembecker, G.; Wohlgemuth, K. Cryst. Growth Des., 2016, 16, 6797-6803.

(23) Wohlgemuth, K.; Ruether, F.; Schembecker, G. Chem. Eng. Sci., 2010, 65, 1016-1027.

(24) Roebuck, J. R. Proc. Natl. Acad. Sci. U. S. A., 1926, 12, 55-58.

(25) Yang, X.; Wang, X.; Ching, C. B. J. Chem. Eng. Data, 2008, 53, 1133-1137.

(26) Hayashi, K.; Matsuda, T.; Takeyama, T.; Hino, T. Agr. Biol. Chem., 1966, 30, 378-384.

(27) Kashchiev, D.; Verdoes, D.; van Rosmalen, G. M. J. Cryst. Growth, 1991, 110, 373-380.

(28) Jiang, S.; ter Horst, J. H. Cryst. Growth Des., 2011, 11, 256-261.

(29) Little, L. J.; Sear, R. P.; Keddie, J. L. Cryst. Growth Des., 2015, 15, 5345-5354.

(30) Laval, P.; Crombez, A.; Salmon, J. B. Langmuir, 2009, 25, 1836-1841.

(31) Diao, Y.; Myerson, A. S.; Hatton, T. A.; Trout, B. L. Langmuir, 2011, 27, 5324-5334.

(32) Mullin, J. W.; Raven, K. D. Nature, 1962, 195, 35-38.

(33) O’Grady, D.; Barrett, M.; Casey, E.; Glennon, B. Chem. Eng. Res. Des., 2007, 85, 945952. 
(34) Kadam, S. S.; Kramer, H. J. M.; ter Horst, J. H. Cryst. Growth Des., 2011, 11, 12711277.

(35) Mohan, R.; Myerson, A. S. Chem. Eng. Sci., 2002, 57, 4277-4285. 


\section{FOR TABLE OF CONTENTS USE ONLY}

\section{Table of contents graphic:}

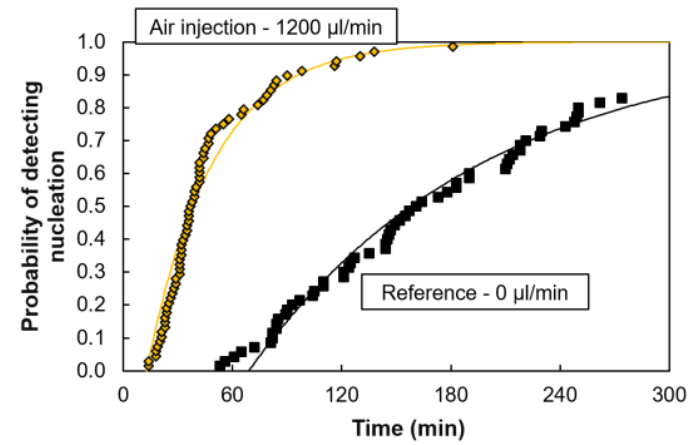

\section{Synopsis:}

Injection of saturated air was investigated as a method to enhance crystallization kinetics in batch crystallizers. The impact on primary nucleation was studied independently from the impact on turbidity build-up after the first nucleation event. Results show a consistently faster turbidity build-up for two model compounds, and an effect on primary nucleation that depends on the gas flow rate. 